\title{
HOMEOPATIA: PRÁTICA MÉDICA COADJUVANTE
}

\author{
Marcus Zulian Teixeira
}

Trabalho realizado pela Disciplina "Fundamentos da Homeopatia" da Faculdade de Medicina da Universidade de São Paulo

\section{*Correspondência}

Rua Teodoro Sampaio, 352/128.

Cep: 05406-000. São Paulo/ SP.

Tel.: (11) 3083-5243

Fax: (11) 3082-6980

marcus@homeozulian.med.br

\section{RESUMO}

Em vista do binômio saúde-doença da concepção homeopática abranger aspectos diversos da individualidade humana, a escolha do medicamento deve englobar as características psíquicas, emocionais, gerais e físicas do paciente. Neste processo de "individualização do medicamento", o entendimento da complexidade humana exige tempo e dedicação, encontrando a resposta satisfatória após um conjunto variável de atuações. Atuando de forma coadjuvante às demais práticas médicas, o médico homeopata deve ter consciência de que poderá suspender os medicamentos alopáticos necessários à manutenção da integridade do paciente tão somente quando tiver certeza da ação substitutiva do medicamento homeopático escolhido. Deste modo, estará cumprindo o aforismo hipocrático primo non nocere.

Unitermos: Homeopatia. Diagnóstico Constitucional. Diagnóstico Medicamentoso. Simillimum. Terapêutica. Bioética.

"Falar de medicina 'alternativa' é... como falar de estrangeiros - ambos os termos são vagamente pejorativos e fazem referência a amplas e heterogêneas categorias definidas pelo que não são, em lugar de definir-se pelo que são". (OMS, 2002)

$\mathrm{Na}$ arte da significação (semântica), estudamos as mudanças ou as transições sofridas pelas palavras em seus significados, ao longo do tempo e do espaço. No intuito de caracterizar a homeopatia como modelo terapêutico para o tratamento das enfermidades humanas, inúmeros adjetivos são-lhe atribuídos: medicina alternativa, complementar, não-convencional, coadjuvante, integrativa, etc. Nestas acepções imputadas ao modelo homeopático, importa entendermos o conceito ou a noção do que os termos expressam ou exprimem, pois representam o papel que 0 agente da ação (médico homeopata) deverá desempenhar quando assumir tal ou qual atribuiç̧ão.

Segundo a Organização Mundial de Saúde (OMS), "os termos 'complementar' e 'alternativa' (e, às vezes, também 'não-convencional' ou 'paralela') são utilizados para referir-se a um amplo grupo de práticas sanitárias que não fazem parte da tradição de um país, ou não estão integradas em seu sistema sanitário prevalente", estando a homeopatia encaixada nesta classificação!

Dentro de uma conotação terapêutica, o adjetivo "alternativo" significa "o que se diz ou faz com alternação" ou "que vem ora um, ora outro", descartando a freqüente atuação da homeopatia de forma concomitante a outras práticas médicas. A denominação "complementar" também não condiz com a atuação desta prática no tratamento das enfermidades humanas, pois significa "que serve de complemento" ou "que sucede ao elementar", em contradição às evidências clínicas que apontam para a resolutividade de diversos problemas de saúde tratados exclusivamente pela homeopatia. Assim como para outras formas de tratar distintas das empregadas comumente pelo modelo tradicional, o termo "não-convencional" exprime uma conotação institucional e política para estas atitudes terapêuticas "distintas das amplamente ensinadas nas faculdades de medicina e geralmente utilizadas em hospitais"2.

No termo "coadjuvante", que significa aquele que "coadjuva, ajuda ou concorre para um fim comum", encontramos um significado apropriado para a forma como a terapêutica homeopática deve se colocar perante as demais práticas médicas vigentes, em vista de buscarem, como objetivo comum, o bem-estar físico, psíquico, social e espiritual dos seus pacientes. O adjetivo "integrativo" ("capaz de integrar ou juntar-se, tornando-se parte integrante") também exprime a idéia de atuar de forma integrada com outras abordagens terapêuticas.

Aspectos práticos da terapêutica homeopática impedem que ela se arrogue no direito de atuar, indistintamente, de forma independente e autônoma (não-coadjuvante, não-integrativa) dos demais conhecimentos e práticas da medicina moderna, como a prerrogativa sine qua non de se valorizar a individualização do medicamento homeopático, que significa a aplicação do princípio da semelhança entre a totalidade de sintomas característicos do indivíduo e as manifestações patogenéticas despertadas pelas substâncias nos experimentadores humanos ${ }^{3}$. Apenas o medicamento homeopático corretamente adaptado ao conjunto de sintomas característicos da individualidade enferma (individualizado) poderá promover a reação homeostática almejada, responsável pela cura de enfermidades crônicas e agudas das mais diversas categorias.

A não observância deste pressuposto obrigatório e intrínseco ao modelo homeopático de tratamento das doenças redunda em ineficácia terapêutica, como demonstrou a meta-análise do The 
Lancet publicada em 2005: não foram observadas diferenças estatisticamente significativas quando se comparou a eficácia do placebo versus a eficácia dos tratamentos homeopáticos que desprezaram a individualização do medicamento homeopático [a grande maioria dos ensaios clínicos homeopáticos selecionados apresentava desenhos impróprios à clínica da individualidade, empregando "um mesmo medicamento" ou "uma mesma mistura de medicamentos (complexos homeopáticos)" para uma queixa clínica comum de todos os pacientes, sendo que na análise final nenhum dos oito ensaios clínicos homeopáticos incluídos aplicava a individualização na escolha do medicamento] $]^{4.5}$.

Por outro lado, quaisquer médicos homeopatas honestos, que aproveitem os ensinamentos que a prática clínica lhe demonstra diariamente, sabem que este "processo de individualização medicamentosa" nem sempre é imediato, exigindo consultas e avaliações periódicas no processo gradual de conhecimento do binômio doente-doença e suas suscetibilidades mórbidas individuais. De forma análoga às outras práticas médicas, incertas por natureza, as limitações existentes na homeopatia, no médico homeopata e no paciente exigem um tempo mínimo para que o ajuste satisfatório do medicamento e suas potências ocorram, fazendo do tratamento homeopático uma técnica empírica, na qual os resultados somente serão observados a posteriori da administração da terapêutica.

Assim sendo, o diagnóstico medicamentoso correto poderá ser um processo mais ou menos demorado (horas a dias nos processos agudos; semanas a meses nos processos crônicos), exigindo do médico homeopata uma conduta consciente e ética que impeça a suspensão imediata dos demais medicamentos em uso, desde que necessários e indispensáveis ao bem-estar físico, psíquico, social e espiritual do paciente.

Ao contrário dos episódios benignos, que evoluem de forma satisfatória, causando incômodos suportáveis ao paciente, nas doenças agudas e crônicas graves a intervenção terapêutica pode ser o diferencial entre a vida e a morte.

Todo médico homeopata consciente deve refletir na capacidade pessoal, evidenciada em sua experiência clínica diária, de atingir o diagnóstico precoce do medicamento homeopático individualizado ideal (simillimum), único capaz de atuar em profundidade e estimular a resposta homeostática terapêutica nestes casos complexos. Homeopatas respeitados referem o índice de 20\%-30\% de acerto do medicamento simillimum num curto período de acompanhamento do paciente. Desta forma, 70\%-80\% destes casos graves, que necessitam de drogas alopáticas para a manutenção das funções vitais, estariam desprotegidos e suscetíveis a desenvolverem iatrogenias fatais com a suspensão prematura dos medicamentos em uso.

Desprezando estas premissas inerentes ao modelo, muitos colegas não assumem o caráter "coadjuvante" do tratamento homeopático, suspendendo drogas aloenantiopáticas imprescindíveis à manutenção do equilíbrio orgânico numa primeira consulta, ou mesmo antes de terem a confirmação da resposta clínica do medicamento indicado, desrespeitando critérios fundamentais e seculares da "boa prática médica homeopática".
Como aceitar a suspensão imediata de hipotensores em pacientes hipertensos graves, da insulina em diabéticos tipo I, de anticoagulantes em cardiopatas severos, de broncodilatadores em asmáticos graves, etc., sem que tenhamos total segurança da atuação substitutiva do medicamento homeopático prescrito? Além do possível agravamento da doença de base (AVE, cetoacidose diabética, IAM, crise asmática grave, respectivamente), a suspensão abrupta e indiscriminada dos medicamentos enantiopáticos poderá desencadear a reação paradoxal ou efeito rebote do organismo (reação vital) causando eventos graves e fatais ${ }^{6-8}$. Como desprezar a probabilidade da ocorrência destas iatrogenias nesta conduta homeopática imprudente?

Exemplos deste tipo de conduta inaceitável por parte de colegas "homeopatas" são vivenciados freqüentemente em pronto-socorros ou atendimentos de emergência, transmitindo a falsa idéia de que "a suspensão imediata dos medicamentos alopáticos em uso" representa uma prerrogativa da clínica homeopática. Este preconceito, fomentado pelos casos de insucesso inicial da terapêutica associados à postura irresponsável de médicos, contribui para que a homeopatia encontre dificuldades em ser aceita como uma importante colaboradora no tratamento de inúmeras doenças perante a medicina convencional.

Em vista de ser um modelo de difícil execução, que exige dedicação e estudo constante, a terapêutica homeopática deve ser encarada como "prática médica coadjuvante" perante as demais especialidades médicas, até que se atinja o status medicamentoso ideal (simillimum), que poderá permitir a substituição gradativa das drogas aloenantiopáticas em uso, desde que viável fisiologicamente. Para isto, devemos embasar nossa conduta substitutiva em exames clínicos e subsidiários (bioquímicos, provas de função, imagens, etc.) que atestem o reequilíbrio dos sistemas orgânicos primordialmente alterados, desprezando as suposições da mentalidade "contracultural", avessa aos avanços da ciência contemporânea, que ainda impregna alguns segmentos do movimento homeopático.

Homeopatia é coisa séria! Não pode ser encarada como um deslumbre de médicos "alternativos" que desprezam a integridade de seus pacientes por acreditarem num "poder absoluto e imediato" de qualquer substância homeopática prescrita, desprezando, na maioria das vezes, o critério da individualização medicamentosa, fundamental para o sucesso da terapêutica homeopática.

Para evitarmos estas disparidades, presentes em todas as classes de especialistas despreparados, os cursos de formação e educação continuada em homeopatia deveriam explicitar, de formas claras e objetivas, as limitações temporais do modelo, evitando os exageros da prática médica homeopática displicente, que pode se transformar num instrumento nocivo quando utilizada de forma inconseqüente.

Juntamente com a certeza dos benefícios do tratamento homeopático bem conduzido, que contribui de forma eficaz e efetiva na resolutividade de inúmeras enfermidades humanas, o médico homeopata deve incorporar à sua conduta holística, generalista e integrativa o aforismo hipocrático primo non nocere. 
Conflito de interesse: não há.

\section{SUMMARY}

\section{HOMEOPATHY: COADJUTANT MEDICAL PRACTICE}

Considering that in the homeopathic conception, the binomial health-disease encompasses several aspects of human individuality, choice of the medication should include the patient's psychic, emotional, general and physical characteristics. In this process of "individualization of medication", understanding the human complexity demands time and dedication to finding the satisfactory reply after a variable number of attempts. Acting as coadjutant to other medical practices, the homeopath should be aware that he may only interrupt administration of the allopathic drugs necessary for maintenance of the patient's integrity when he is assured of the substitutive action of the homoeopathic medication chosen. This way, the Hippocratic aphorism primo non nocere will be fulfilled. [Rev Assoc Med Bras 2007; 53(4): 374-6]

KEY wORDS: Homeopathy. Diagnosis Constitutional. Diagnosis Medicamentous. Simillimum. Therapeutics. Bioethics.

\section{REFERÊNCIAS}

I. World Health Organization. WHO traditional medicine strategy 20022005. Geneva; 2002. Avaliable from: http://www.who.int/medicines/ publications/traditionalpolicy/en/index.html.
2. Teixeira MZ, Lin CA, Martins MA. O ensino de práticas nãoconvencionais em saúde nas faculdades de medicina: panorama mundial e perspectivas brasileiras. Rev Bras Educ Med. 2004;28(1):51-60. Disponível em: http://www.abem-educmed.org.br/rbem/pdf/ volume 28 l/ensinos de praticas.pdf.

3. Teixeira $M \bar{Z}$. Panorama da pesquisa em homeopatia: iniciativas, dificuldades e propostas. Diagn Tratamento. 2004;9(3):98-104. Disponível em: http://www.apm.org.br/fechado/d_tratamento/ dt 9ed3/RDT-9\%20(3) 98-104.pdf.

4. Teixeira MZ. Será mesmo o fim da homeopatia? Diagn Tratamento. 2006; II(1):6/-3. Disponível em: http://www.apm.org.br/fechado/ d_tratamento/dt_I led I/RDT\%20 I I ( I)\%206 I-63.pdf.

5. Teixeira MZ. Homeopatia: ciência, filosofia e arte de curar. Rev Med (São Paulo). 2006;85(2):30-43.

6. Teixeira MZ. Evidence of the principle of similitude in modern fatal iatrogenic events. Homeopathy. 2006;95(4):229-236.

7. Teixeira MZ. NSAIDs, Myocardial infarction, rebound effect and similitude. Homeopathy. 2007;96(1):67-68.

8. Teixeira MZ. Bronchodilators, fatal asthma, rebound effect and similitude. Homeopathy. 2007;96(2):135-7.
Artigo recebido: 22/02/07

Aceito para publicação: 19/03/07 